\title{
Robot-Assisted Therapy on Ankle Rehabilitation, A Mini Review
}

\author{
Ashkan Jahanyani ${ }^{1}$, Saeed Karimi Matloub ${ }^{2}$, Rasool Karimi Matloub ${ }^{3}$ and Seyed Ali Hossin \\ Zahraei*1 \\ ${ }^{1}$ Student research committee at Shiraz university of medical sciences Shiraz , Iran
}

${ }^{2}$ Student at Qom university of medical sciences, Iran

${ }^{3}$ Student at Arak university of medical sciences, Iran

*Corresponding author: Seyed Ali Hossin Zahraei, Student research committee at Shiraz university of medical sciences Shiraz , Iran

\begin{tabular}{|c|c|}
\hline ARTICLE INFO & ABSTRACT \\
\hline Received: 栔 May 25, 2021 & $\begin{array}{l}\text { The aim of this study was to supply a scientific review of studies that investigated the } \\
\text { effectiveness of robot-assisted therapy on ankle motor and performance recovery from }\end{array}$ \\
\hline
\end{tabular}

Keywords: Robot-Assisted Therapy; Ankle Rehabilitation; Clinical Effectiveness

Citation: Ashkan Jahanyani, Saeed Karimi Matloub, Rasool Karimi Matloub, Seyed Ali Hossin Zahraei. Robot-Assisted Therapy on Ankle Rehabilitation, A Mini Review. Biomed J Sci \& Tech Res 36(4)-2021. BJSTR. MS.ID.005894.

\section{Introduction}

The ankle is that the commonest site of sprain injuries within the physical body, with over 23,000 cases estimated to occur per day within the us [1]. Robotics technology can provide an overdue transformation of rehabilitation clinics from labor-intensive operations to technology-assisted operations also as an upscale stream of knowledge which will facilitate patient diagnosis, customization of the therapy, and maintenance of patient records (at the clinic and at home) [2]. Currently, there are mainly two kinds of robot-assisted ankle rehabilitation devices: people that are wearable devices mainly aiming at improving ankle performance during gait and people that are platform based devices focusing solely on improvement of ankle performance [3-5].

\section{Method}

The literature search was limited to English-language articles (i.e., journal articles, extended abstracts, and conference proceedings) published in the following electronic databases recommended by a librarian : PubMed, EMBASE (Excerpta Medical database), MEDLINE (OvidSP), CDS (Cochrane database of systematic reviews), Web of Science, Scopus, Compendex, IEEE Xplore, ScienceDirect, Wiley Online Library, Digital Dissertations, Academic Search Premier, SpringerLink. The electronic search terms were "'Ankle*' AND 'Robot*' AND ('rehabilitat*' or 'treat')". A free search in Google Scholar was also conducted and valuable references listed in relevant publications were screened, which made our search as systematic and complete as possible.

\section{Results and Discussion}

Several studies have shown that gait performance is affected by ankle muscle strength (in stroke [6] and spastic diplegia CP [7]) and ankle joint position [8]. One study [9] concluded that the isokinetic torques of the paretic ankle plantar flexors had moderate to high correlations with gait and stair-climbing speeds. Another [10] revealed that the dorsiflexors strength was the foremost important 
factor for gait velocity and dynamic spasticity was the foremost important determinant for gait spatial symmetry. It also showed that adequate ankle control during gait was important for normal gait pattern. To some extent, however, a functional recovery of gait are often thought of as an indicator of ankle functional recovery.

\section{Conclusion}

Even though a variety of robot-assisted ankle rehabilitation devices and control strategies are available for people with ankle disability, the foremost effective ankle rehabilitation device and control algorithm remains vague.

\section{References}

1. Hertel J (2002) Functional anatomy, pathomechanics, and pathophysiology of lateral ankle instability. J Athl Train 37(4): 364-375.

2. Krebs HI, Palazzolo JJ, Dipietro L, Ferraro M, Krol J, et al. (2003) Rehabilitation robotics: performance-based progressive robot-assisted therapy. Autonomous Robots 15: 7-20.

3. Mohammed S, Amirat Y, Rifai H (2012) Lower-limb movement assistance through wearable robots: state of the Art and challenges. Advanced Robotics 26(1): 1-22.

\section{ISSN: 2574-1241}

DOI: $10.26717 /$ BJSTR.2021.36.005894

Seyed Ali Hossin Zahraei. Biomed J Sci \& Tech Res

(c) (9) This work is licensed under Creative

Submission Link: https://biomedres.us/submit-manuscript.php
4. Hesse S, Schmidt H, Werner C, Bardeleben A (2003) Upper and lower extremity robotic devices for rehabilitation and for studying motor control. Curr Opin Neurol 16(6): 705-710.

5. Senanayake C, Senanayake SMNA (2009) Emerging robotics devices for therapeutic rehabilitation of the lower extremity. In EEE/ASME international conference on advanced intelligent mechatronics; July 1417. Singapore: Institute of Electrical and Electronics Engineers Inc, pp. 1142-1147.

6. Nadeau S, Gravel D, Arsenault AB, Bourbonnais D (1999) Plantarflexor weakness as a limiting factor of gait speed in stroke subjects and the compensating role of hip flexors. Clin Biomech 14(2): 125-135.

7. Ross SA, Engsberg JR (2007) Relationships between spasticity, strength, gait, and the GMFM-66 in persons with spastic diplegia cerebral palsy. Arch Phys Med Rehabil 88(9): 1114-1120.

8. Lin SI (2005) Motor function and joint position sense in relation to gait performance in chronic stroke patients. Arch Phys Med Rehabil 86(2): 197-203.

9. Kim CM, Eng JJ (2003) The relationship of lower-extremity muscle torque to locomotor performance in people with stroke. Phys Ther 83(1): 49-57.

10. Lin PY, Yang YR, Cheng SJ, Wang RY (2006) The relation between ankle impairments and gait velocity and symmetry in people with stroke. Arch Phys Med Rehabil 87(4): 562-568.

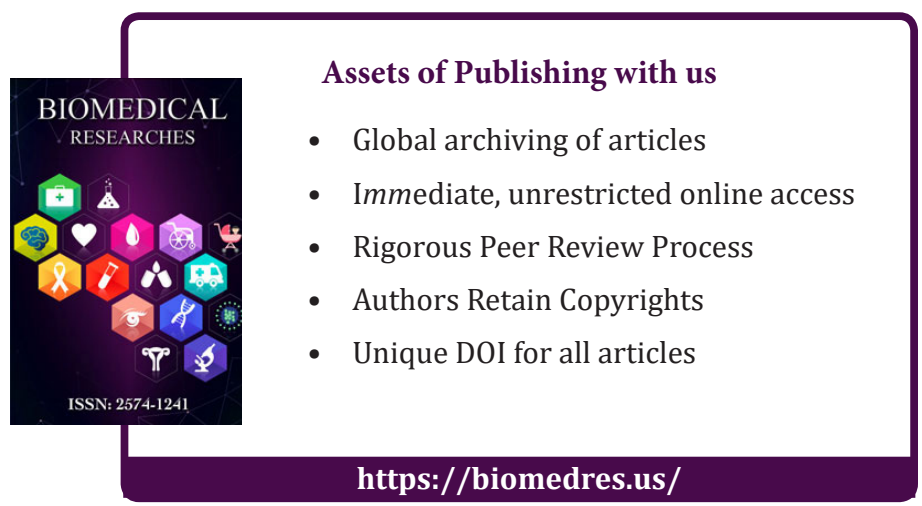

